\title{
Carcinogenic Mixture
}

National Cancer Institute

\section{Source}

National Cancer Institute. Carcinogenic Mixture. NCI Thesaurus. Code C45189.

A compound that consists of a combination of more than one substance that can cause cancer in humans. ( $\mathrm{NCl05)}$ 